(c) American Dairy Science Association, 2004.

\title{
ADSA Foundation Scholar Award: Defining Dairy Flavors
}

\section{MaryAnne Drake}

Dept. Food Science, Southeast Dairy Foods Research Center

North Carolina State University, Raleigh 27609-7624

\section{ABSTRACT}

Production and consumption of dairy foods continue to increase annually. Further, new ingredient applications for dairy foods continue to expand. With continued production and consumption, there is also increased competition. Increased competition exists regionally, nationally, and globally. Processors as well as product developers must find ways to maximize existing markets and expand into new markets. A consistent high quality product is necessary to maintain competitiveness. Although microbial safety and stability are key ways to define quality, flavor is one method of defining quality that is often assumed or overlooked. The aggressive and competitive nature of today's market demands more precise and powerful tools for defining flavor and flavor quality. Traditional as well as more recent methods for evaluating dairy flavor are reviewed. The application of defining sensory flavors to fundamental research on flavor chemistry, product understanding, and effective marketing is addressed. (Key words: flavor, sensory analysis, flavor chemistry, cheese flavor)

\section{INTRODUCTION}

Consumption of dairy foods in the US is greater than ever as are the number of ingredient applications for dairy foods. Today's market is also highly competitive with regional, national, and global competition among dairy foods as well as competition from non-dairy foods and ingredients. Consumers have a wide variety of products and brands to choose. Maintaining and expanding market share are critical to competitiveness. A high quality, consistent product is necessary to attract and maintain customers.

Microbial quality, shelf life, shelf stability, or a combination of these have been and will remain key ways to define a high quality product (Boor, 2001). However, flavor is another way to define quality and market shares. Sensory perception is always important, and

Received October 11, 2003.

Accepted November 10, 2003

Email: mdrake@unity.ncsu.edu. flavor is a crucial sensory concept. A customer (endproduct manufacturer that uses dairy foods as ingredients or the consumer at the grocery store) will not continue to purchase a product that does not live up to flavor expectations. Within dairy products, especially cheeses, there are a myriad of flavors and flavor profiles that are possible because of processing and formulation. Different customers will have different expectations of flavor. Understanding and defining customer expectations of flavor are necessary to deliver target flavor. An increased understanding of product flavor and flavor stability and linkage of specific flavors to volatile flavor compounds are required. Defined sensory languages are necessary to achieve these goals. Thus, development of methods to define and describe flavor is important for precise communication in research and marketing. This review will primarily focus on Cheddar cheese to demonstrate the applications and power of defined sensory languages.

\section{Sensory Analysis Methods}

Sensory analysis is a compilation of different tools or tests that can be used for subjective or objective evaluation of food sensory properties. Selection of the appropriate tool or test for a specific objective is required to obtain appropriate and optimal results. One group of sensory tools for dairy products is quality judging. These tests are the traditional grading and judging tools that have been used by the dairy industry to assess overall quality based on previously defined defects (Bodyfelt et al., 1988). These techniques were established in the early 1900s, long before sensory analysis evolved into a scientific area of research. Grading was established by the Federal government with the foundation of the Office of Markets (currently known as the Agricultural Marketing Service) in 1913 (www.ams.usda.gov). Dairy products judging developed as a way to stimulate student interest and education, and the first contest was held in 1916 (Bodyfelt et al., 1988). Both grading and judging operate on the same premise. Products receive quality scores for appearance, flavor, and/or texture based on the presence or absence of predetermined defects. Generally 1 to 2 experts are used, and evaluations are not repli- 


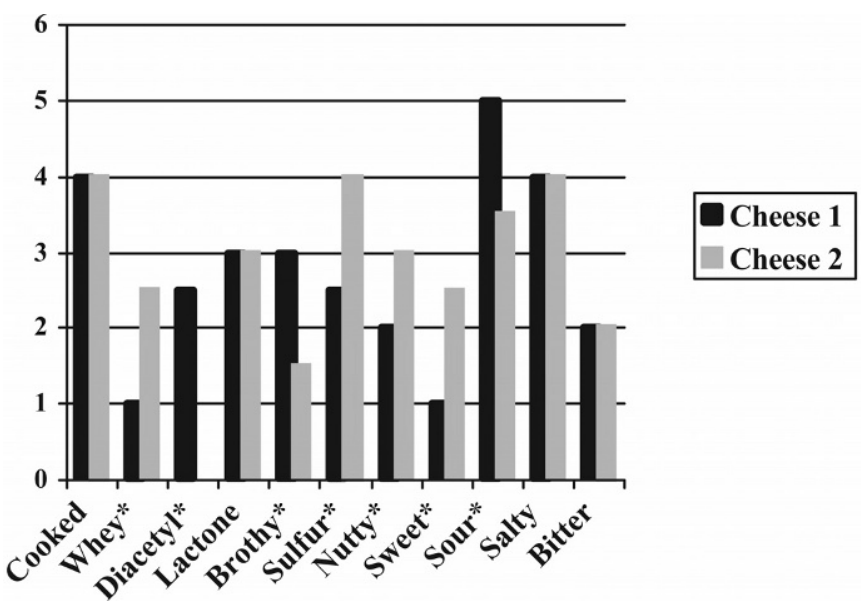

Figure 1. Descriptive sensory profiles of two Cheddar cheeses that received the same grade by traditional grading techniques. The asterisk $(*)$ denotes attributes that were significantly different between the two cheeses $(P<0.05)$.

cated. Although a useful tool for student education and rapid assessment of quality in an industrial setting, grading or judging scores cannot be statistically analyzed because of unequal defect score assignment. Scores are also not qualitative and quantitative of all of the attributes in a product. Cheeses judged to be of similar quality by the same judge may differ significantly in defined sensory characteristics (Delahunty and Murray, 1997). Two cheeses may receive identical AA grades, indicating that they are both good quality (based on presence or absence of pre-defined defects). However, specific differences may exist in descriptive flavor profiles (Figure 1). These differences can significantly impact research interpretations and customer or consumer preferences. Further, what represents "good" and "bad" quality to an expert grader are not necessarily synonymous to the cheese consumer (McBride and Hall, 1979). Consumer concepts and preferences for cheese flavor profiles are diverse. Thus, cheese grade results cannot be used in research to superimpose consumer preferences. For these reasons, grading and judging are not ideal tools for cheese flavor research.

Mainstream sensory tests can be divided into two categories: affective and analytical (Lawless and Heymann, 1998; Meilgaard et al., 1999). Affective tests involve consumers and their perceptions of acceptability as well as other consumer concepts. Such tests are useful for exploring the role that flavor, as well as texture and appearance, play in consumer choice and acceptability. Exploration of other consumer concepts, such as cheese flavor, Cheddar cheese flavor, and aged cheese flavor intensity, are also evaluated with these types of tests. Applications of these tests to flavor research will be addressed later. One key issue is that affective tests or consumer acceptability evaluate consumer responses. As such, untrained individuals, who are ideally consumers of the product, should be used. Moreover, consumer responses vary from individual to individual. Thus, a large number of consumers need to be polled if a reasonable projection of consumer responses is to be obtained. A minimum of 50 (untrained) individuals is recommended for these types of evaluations and more are required if market segmentation is evaluated (Lawless and Heymann, 1998).

Analytical tests involve the use of screened or trained panelists whose responses are treated as instrumental data. Such tests include discriminatory tests (difference and threshold) and, the most powerful tool in the sensory arsenal, descriptive analysis. The purpose of descriptive analysis is to train a group of individuals to evaluate specific sensory properties analytically. Descriptive analysis is the tool of choice for qualitatively and quantitatively differentiating foods and for exploring and defining the relationships between sensory and instrumental perception. Descriptive analysis of any food requires a descriptive technique and a lexicon or language to describe the sensory properties. There are several valid approaches to descriptive analysis (Murray et al., 2001; Drake and Civille, 2003). These approaches include Flavor Profile Method, Quantitative Descriptive Analysis, the Spectrum technique, and other techniques that have incorporated parts of two or more of the previous methods. Sensory languages can be identified for any dairy food of interest using any of these approaches. Panelist selection, scales and scale usage, and training are critical parts of any descriptive texture analysis approach. These specifics are reviewed elsewhere (Drake and Civille, 2003; Meilgaard et al., 1999). A panel or group of individuals (generally 8 to12) is used for descriptive sensory analysis rather than 1 or 2 experts. A panel of individuals is used because factors such as age, saliva flow, and onset of fatigue vary between panelists. Panelists also vary in sensitivity to particular stimuli, and it is highly probable that they also vary in their concentration-response functions. Panelists, even highly trained panelists or experts, can vary in sensory function because of mood or foods previously eaten. Thus, a group or panel is used rather than 1 or 2 individuals for consistent results.

One important issue not to be overlooked is panelist training and replication. Although descriptive analysis does not require expensive instrumentation, time and training are required. The old adage "you reap what you sow" directly applies. A good descriptive analysis panel will require training by an experienced 
Table 1. Languages developed and used for sensory analysis of Cheddar cheese flavor.

\begin{tabular}{|c|c|}
\hline Reference & Descriptive vocabularies \\
\hline Drake et al., 2001, 2002, 2003a,b,c ${ }^{1}$ & $\begin{array}{l}\text { Flavor: Cooked, whey, diacetyl, milk fat/lactone, fruity, overall sulphur, sulfur/eggy, sulfur/match, } \\
\text { free fatty acid, brothy, nutty, catty, cowy/phenolic, age, yeasty, moldy/musty, methyl } \\
\text { ketone/bleu, oxidized, waxy/crayon, fecal, bell pepper, rosy/floral, scorched, bitter, salty, } \\
\text { sweet, sour, umami, prickle/bite }\end{array}$ \\
\hline McEwan et al., 1989 & $\begin{array}{l}\text { Odor: Strength, creamy/milky, sour, rindy, manure } \\
\text { Flavor: Creamy/milky, strength, sour, manure, salty, acid, smokey, rindy }\end{array}$ \\
\hline $\begin{array}{l}\text { Muir and Hunter, } 1992 \\
\text { Banks et al., } 1993 \\
\text { Muir et al., } 1996 \\
\text { Muir et al., } 1997\end{array}$ & $\begin{array}{l}\text { Odor: Intensity, creamy, sulfur, fruity, nutty, rancid, other } \\
\text { Flavor: Cheddar intensity/overall intensity, creamy/milky, sour/acid, sulfur/eggy, fruity/sweet, } \\
\text { nutty, rancid, bitter, cowy, unclean/manurial, salty, other }\end{array}$ \\
\hline $\begin{array}{l}\text { Murray and Delahunty, 2000a,b, } c^{1} \\
\text { Bogue et al., } 1999 \\
\text { Fenelon et al., } 2000\end{array}$ & $\begin{array}{l}\text { Aroma: Pungent, caramel, sweaty/sour, sweet, creamy, fruity } \\
\text { Flavor: Pungent, caramel, sweaty, creamy, fruity, buttery, rancid, Cheddary, mushroom, moldy, } \\
\text { nutty, smoky, soapy, processed, sweet, salty, acidic, bitter, astringent, strength, balanced }\end{array}$ \\
\hline Roberts and Vickers, 1994 & $\begin{array}{l}\text { Aroma: Buttery, fatty, fruity, fermented, moldy, nutty, sweaty/sour, pungent, rancid, smokey, } \\
\text { spoiled dairy, vinegary } \\
\text { Flavor: Acid, acid bite, astringent, barny, bitter, buttery, cardboard, chemical, fatty, fruity, } \\
\text { metallic, milky, moldy, peppery, sweaty/sour, rancid, salty, sharp, smokey, soapy, } \\
\text { diacetyl (yogurt), sweet } \\
\text { After taste: Acid, bitter, milky, smokey, fishy, moldy, peppery, soapy, sweaty/sour }\end{array}$ \\
\hline
\end{tabular}

${ }^{1}$ Published language has definitions and references; adapted from Delahunty and Drake (accepted).

panel leader. The number of hours of training varies with the food, the number of terms, and the modality(ies) used. For instance, texture generally requires less training than flavor. Once trained, a descriptive panel operates as an instrument, meaning that data must be replicated, as with any instrument (Lawless and Heymann, 1998). The panelists are units of the instrument, and each panelist should replicate each sample.

\section{Development of Sensory Languages for Cheddar Cheese Flavor}

Sensory languages or lexicons are the basis for descriptive sensory analysis. A flavor lexicon is simply a set of words to describe the flavor of a product or commodity. A lexicon is then applied or practiced using descriptive sensory analysis techniques. Lexicon development and attributes have been recently reviewed (Drake and Civille, 2003). Sensory lexicons should be representative, discriminating, descriptive, and nonredundant with regard to the food they describe. Another lexicon attribute that has received more attention in recent years is that the lexicon attributes have precise and clear meaning, not only to the panelists for optimum performance, but to the reader of the subsequent publication.

Descriptive sensory analysis has been applied as a tool to interpret a myriad of research objectives in dairy foods research in recent years as well as product development goals. However, these results are difficult to interpret or reproduce if the lexicon used does not have clear and precise meaning to the reader. Verbal definitions as well as food or chemical references are required for maximum language clarity. Descriptive sensory analysis has been applied to a wide variety of cheeses (Delahunty and Drake, accepted). Several sensory languages have been developed specifically for evaluation of Cheddar cheese flavor; however, only a few (Murray and Delahunty, 2000b; Drake et al., 2001) have been published with definitions and references for each descriptor (Table 1). The lack of definitions, references, or both hinders precise communication and limits the application of the language. As seen in Table 1, descriptors alone do not convey a single meaning or concept, but can mean different things to different people unless clear definitions and references are provided. A well-defined lexicon can be effectively utilized across different panel sites and by different panel leaders (Drake et al., 2002).

Another key issue is that a representative sample set be used for language identification. For a language to be robust and able to describe differences between products precisely, the entire range of products should be used for language development. If the objectives of the sensory language are simply to describe flavors observed among a set of experimental treatments, identifying all possible flavors may be simple and straightforward, but becomes more difficult if the goal is to develop a language to differentiate an entire commodity or product line (e.g., Cheddar cheese). Sensory languages are not absolute and can evolve with time as additional flavors are identified. Defined sensory 


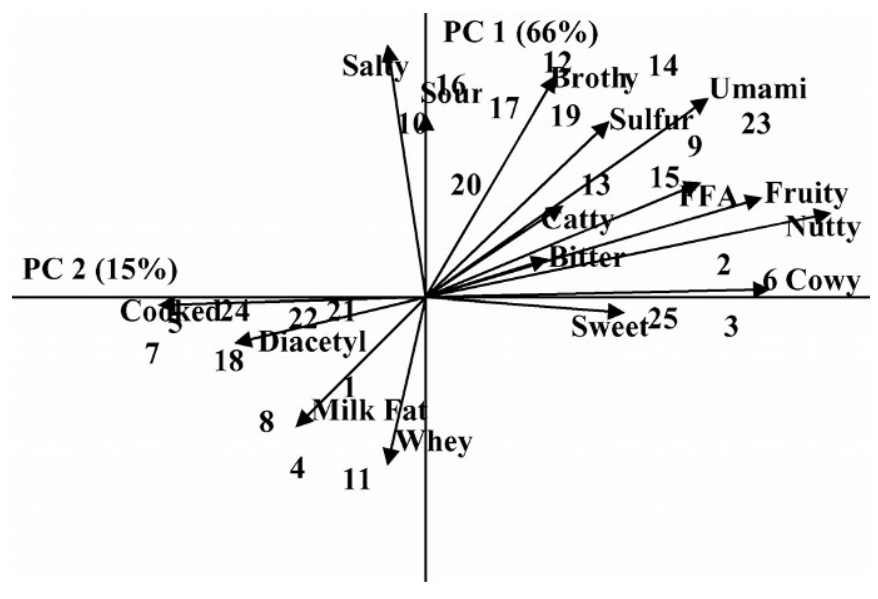

Figure 2. Flavor variability among 25 Cheddar cheeses documented by descriptive sensory analysis using a defined sensory language for Cheddar cheese. Cheeses are represented by numbers. (Adapted from Drake et al., 2001). PC 1 = Principal component 1; PC 2 = principal component 2 .

languages are a powerful platform for increased product understanding, exploring chemical sources of specific flavors, and consumer preferences.

\section{Product Understanding}

One of the primary applications of a defined sensory language is to increase understanding of product flavor and flavor variability. Inherent product variations, processing effects, and storage effects can be effectively compared from a sensory perspective. Understanding product variability can aid in identification of ways to market or develop specific products effectively or effectively control flavor development. Figure 2 shows the flavor variability observed among a sample set of 25 different Cheddar cheeses of varying age. Banks et al. (1993) used descriptive analysis to determine sensory properties of low fat Cheddar cheese; factory and farmhouse Cheddars have also been compared (Muir et al., 1997). Descriptive sensory analysis has been widely used to determine the effect of starter and adjunct cultures on Cheddar cheese flavor (Muir et al., 1996; Drake et al., 1996, 1997; Lynch et al., 1999; Broadbent et al., 2002, Banks et al., 2001). The impact of other processing variables, such as different milk sources, flavoring, or both, can also be compared (Rehman et al., 2003a,b,c).

Sensory languages have been used to demonstrate regional differences within Comte (Monnet et al., 2000). Drake et al. (2003c) conducted a collaborative study with researchers in Ireland and New Zealand to demonstrate international differences in Cheddar cheese flavor, and current work is addressing the ques- tion of regional differences in US Cheddar cheeses. Although Cheddar cheese is the primary example used in this review, it is important to note that similar work has recently been conducted with fluid milk and dried dairy ingredients, which have developed and used defined sensory languages to use as powerful research tools. Chapman et al. (2001) developed a sensory language to differentiate and describe ultrapasteurized milks. A lexicon has also been developed to differentiate dried dairy ingredients (Drake et al., 2003b) (Figure 3). Current research is focused on similar work with fluid chocolate milks. Defined languages have also been developed for cheese texture to enhance understanding of rheological and functional properties (Brown et al., 2003; Foegeding et al., 2003).

\section{Links to Flavor Chemistry}

A crucial aspect to defining and understanding dairy flavors is identification of chemical compounds responsible for specific sensory perceived flavors. In fermented foods such as cheese, where procedure and ripening temperatures play a large role, such findings are the building blocks for establishing ways to link specific flavors to technology of cheese production. Initial work with cheese flavor chemistry focused solely on volatile isolation and identification. However, recent work has focused on linking volatile compounds to specific flavors and on design of instrumental techniques to simulate flavor release from foods as they are broken down in the mouth (Deibler et al., 2001). Flavor chemistry of Cheddar cheese has been recently reviewed, and many flavors have been linked to specific volatile compounds (Singh et al., 2003).

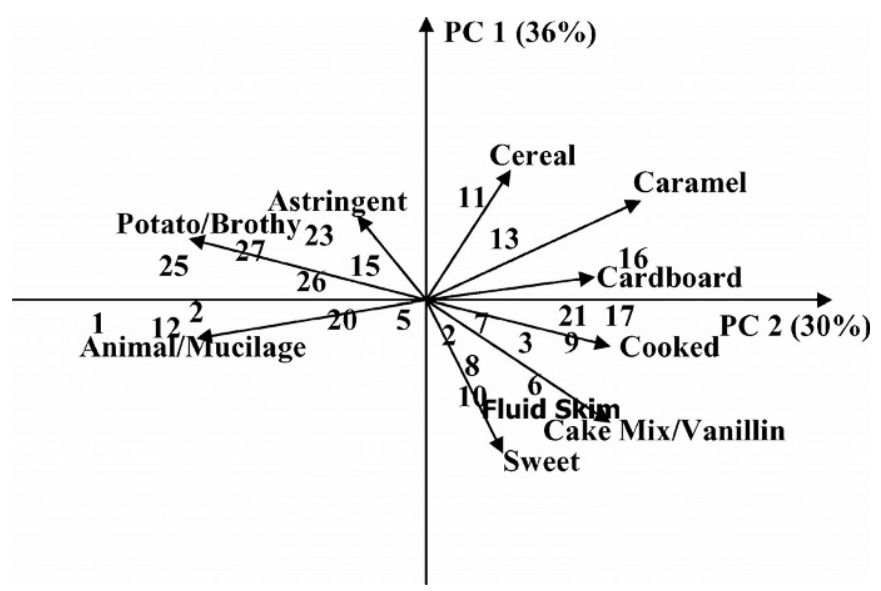

Figure 3. Flavor variability among low heat skim milk powders less than 3 mo old. Rehydrated milk powder are represented by numbers. PC 1 = Principal component 1; PC 2 = principal component 2. 
Pinpointing compounds responsible for specific flavors in dairy products is not straightforward in most cases. Flavor chemistry alone poses a large challenge. Numerous volatile compounds can be isolated from a given dairy food such as cheese, yet only a fraction is present at concentrations higher than their sensory threshold (McGorrin, 2002; Singh et al., 2003). The list of key volatile compounds can be narrowed down by gas chromatography/olfactometry. In this technique, the individual compounds in the gas chromatography effluent are sniffed and described by trained panelists (Friedrich and Acree, 1998; Van Ruth and O'Connor, 2001). Although quite time-consuming, volatiles that are detected in this manner indicate that they are likely present at concentrations higher than sensory threshold in the food. Using this approach, key aroma-active volatile components in mild and aged Cheddar cheeses have been investigated (Milo and Reineccius, 1997; Suriyaphan et al., 2001; Zehentbauer and Reineccius, 2002). These techniques do not take into account matrix effects. Threshold and sensory character of compounds can be impacted by food matrix, and descriptive sensory analysis of the finished product is needed to aid in interpretation of results.

A list of volatile compounds, even a list of key aroma compounds, is still a simple list of compounds. Defining what role each compound plays is more complex. A defined sensory language should be applied to the product to profile the perceived flavors present. Subsequently, statistical analysis can be applied with large data sets to pinpoint further the key compounds and flavors, or a thorough evaluation of the list of aromaactive compounds combined with an understanding of the defined sensory language can lead to identification of key compounds. Model system analysis should then be used to provide further evidence of the role that a specific compound or compounds play. Such studies have been conducted with Swiss and Emmental cheeses without the use of a defined sensory language (Preinenger et al., 1996; Rychlik et al., 1997).

Suriyaphan et al. (2001) investigated sources of cowy/barny and earthy/bell pepper flavors in farmhouse Cheddar cheeses. Flavor profiles of cheeses were documented by descriptive sensory analysis with a defined Cheddar sensory language followed by instrumental analysis with gas chromatography/olfactometry. From a list of 27 odor-active compounds, 2 were selected for model system analysis. Compounds were spiked into mild Cheddar cheeses (that did not exhibit cowy/barny or earthy/bell pepper flavors) across the concentration range that was found in the farmhouse Cheddar cheeses. Cheese models were subsequently evaluated by a trained sensory panel using the defined

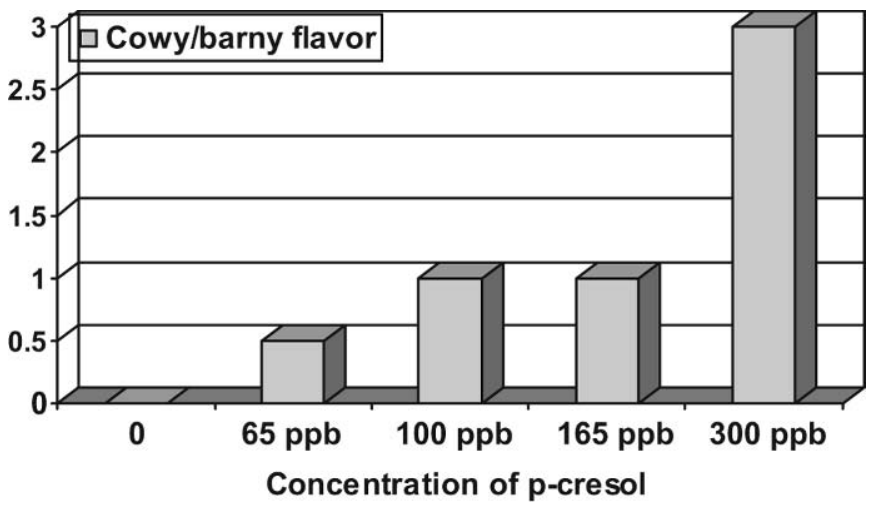

Figure 4. Cowy/barny flavor intensity in mild Cheddar cheese when p-cresol is spiked into cheeses across the concentration range naturally found in aged Cheddar cheeses with cowy/barny flavor. (Adapted from Suriyaphan et al., 2001).

cheese flavor language. Figures 4 and 5 show the perceived sensory intensities of cowy/barny and earthy/ bell pepper flavors in cheese models as concentrations of p-cresol and 2-isopropyl-3-methoxypyrazine were increased. These studies do not indicate that these compounds are exclusively responsible for these flavors, but they do provide compelling evidence that these compounds can be a source of these flavors in Cheddar cheeses. A similar approach was recently applied to investigate the volatile components of Chevrestyle goat cheeses and the specific roles that free fatty acids play in the characteristic waxy/animal flavor of these cheeses (Carunchia-Whetstine et al., 2003). Karagül-Yüceer et al. (2003, accepted) used model systems and descriptive sensory analysis to confirm key volatile compounds identified by instrumental analysis in fresh skim milk powder and rennet casein.

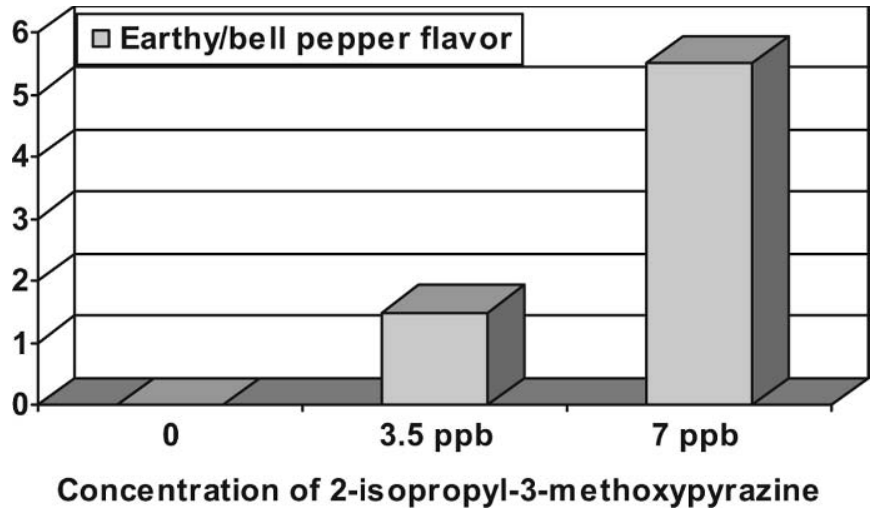

Figure 5. Earthy/bell pepper flavor intensity in mild Cheddar cheese when 2-isopropyl-3-methoxypyrazine is spiked into cheeses across the concentration range naturally found in aged Cheddar cheeses with earthy/bell pepper flavor. (Adapted from Suriyaphan et al., 2001). 
Ideally, these established links can be combined with our understanding of processing effects or microbial physiology to enhance or control specific flavors effectively. For example, a chemical compound may be confirmed by flavor chemistry and model systems as the source of a desirable defined flavor in Cheddar cheese. Current knowledge of starter culture physiology may enable identification of a starter or adjunct that produces the identified compound in high amounts. Production of cheese with the identified starter should ensue to evaluate and establish further the links between flavor chemistry and production technology. Of course, flavor, specifically Cheddar cheese flavor, is very complex and is based on an appropriate balance of numerous volatile components (Singh et al., 2003). There may not be any magic bullets. Effective links between Cheddar cheese flavor and production technology will require extensive future research and should be an industry goal.

\section{Understanding the Consumer}

Defining dairy flavors also enhances more powerful and effective marketing. With the numerous different flavor profiles available in products such as cheeses, flavored milks, and yogurts, knowledge of target flavor profiles for target consumer market segments is crucial. What is desirable to one consumer may not be to another. Ideally, marketing should address target flavor profiles to target consumer markets. Affective sensory tests, which measure consumer responses, can provide information on consumer likes and dislikes. However, they do not provide definitive quantitative information on specific flavor profiles. Consumers may use terms that are ambiguous, have multiple meanings, are associated with "good" or "bad", or are combinations of several terms. This type of information does not lend itself to concrete information for identification of target flavor profiles.

Defined sensory languages provide the key to unlocking consumer terminology and interpretation of target flavor profiles for specific market segments. A group of products are documented with descriptive analysis and then tested with consumers. The analytical descriptive properties that describe exactly what attributes are perceived and at what levels are related to consumer preferences using combinations of multivariate techniques. Lawlor and Delahunty (2000) used this approach to identify distinct consumer liking clusters for Irish specialty cheeses and for Irish factory and farmstead Cheddar cheeses (Murray and Delahunty, 2000c). More recently, Young et al. (2004) applied these techniques, descriptive sensory analysis followed by consumer acceptance testing, to US Cheddar

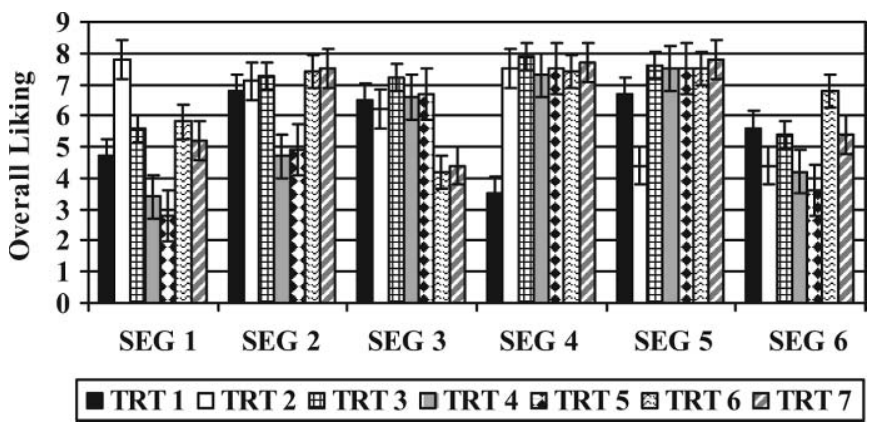

Figure 6. Overall acceptability scores for 7 Cheddar cheeses of varying ages and flavor profiles within different consumer segments. Acceptability was scored on a 9-point hedonic scale where $1=$ dislike extremely to 9 = like extremely. (Adapted from Young et al., 2003). $\mathrm{TRT}=$ Cheese $; \mathrm{SEG}=$ consumer segment .

cheeses. Seven Cheddar cheeses, diverse in age and flavor profile, were evaluated using a defined sensory language followed by consumer testing. A wide variation in consumer acceptance was observed among the seven Cheddar cheeses with six distinct consumer market segments (Figure 6), each with their own specific profile of likes and dislikes with Cheddar cheese. Such knowledge can be used to market the "right cheese" to the "right consumer" effectively, which is powerful information in today's highly competitive market.

\section{Global Understanding}

Today, competition exists at multiple levels: regional, national, and global. The US dairy industry should compete on the global market effectively. To do so, an understanding of international products and international perception is required. Work in the European Union has addressed international differences in dairy flavor and cultural perception (Hunter and McEwan, 1998; Nielson and Zannoni, 1998). Research has not included the US or oceanic countries (Australia, New Zealand). Drake et al. (2003c) recently described the flavor differences among US, Irish, and New Zealand Cheddar cheeses. Distinctive countryof-origin differences in flavor were noted with a small sample set of Cheddar cheeses. Descriptive panels in each country evaluated the Cheddar cheeses, using their own anchored and defined lexicons. Differentiation of Cheddar cheeses was similar at each site, further confirming the distinctive flavor differences in Cheddar cheeses from each country and also providing crucial information on differences in cross-cultural perception and description of Cheddar cheese flavor. Such knowledge is crucial for global marketing and not possible without a defined sensory language. 


\section{CONCLUSIONS}

The dairy industry has made great leaps and bounds in defining and understanding flavor. Similar progress has been made with texture and rheology. The ability to describe and document flavor is pivotal for enhancing knowledge and understanding of dairy foods flavor. Such knowledge can be widely applied for both fundamental and applied research as well as marketing.

\section{ACKNOWLEDGMENTS}

The author is grateful to the California Dairy Research Foundation and Dairy Management, Inc. for financial support of research. Thanks is extended to long-time collaborators Gail Vance Civille, Keith Cadwallader, and Patrick Gerard. A special thanks to Joe O'Donnell for encouragement and mentoring.

\section{REFERENCES}

Banks, J. M., E. A. Hunter, and D. D. Muir. 1993. Sensory properties of low fat Cheddar: Effect of salt content and adjunct culture. J. Soc. Dairy Technol. 46:119-123.

Banks, J. M., M. Yvon, J. C. Gripon, M. A. de la Fuente, E. Y. Brechany, A. G. Williams, and D. D. Muir. 2001. Enhancement of amino acid catabolism in Cheddar cheese using $\alpha$-ketoglutarate:amino acid degradation in relation to volatile compounds and aroma character. Int. Dairy J. 11:235-243.

Bodyfelt, F. W., J. Tobias, and G. M. Trout. 1988. The Sensory Evaluation of Dairy Products. Van Nostrand Reinhold, New York, NY.

Bogue, J. C., C. M. Delahunty, M. Henry, and J. M. Murray. 1999. Market-oriented methodologies to optimise consumer acceptability of Cheddar-type cheese. Br. Food J. 101:301-316.

Boor, K. J. 2001. Fluid dairy product quality and safety. J. Dairy Sci. 84:1-11.

Broadbent, J. R., M. Barnes, C. Brennand, M. Strickland, K. Houck, M. E. Johnson, and J. L. Steele. 2002. Contribution of Lactococcus lactis cell envelope proteinase specificity to peptide accumulation and bitterness in reduced fat Cheddar cheese. Appl. Environ. Microbiol. 68:1778-1785.

Brown, J. A., E. A. Foegeding, C. R. Daubert, and M. A. Drake. 2003. Changes in rheological and sensorial properties of young cheeses as related to maturation. J. Dairy Sci. 86:3054-3067.

Carunchia-Whetstine, M., Y. Karagul-Yuceer, Y. K. Avsar, and M. A. Drake. 2003. Aroma-active components of fresh goat cheeses. J. Food Sci. 68:2441-2447.

Chapman, K. W., H. T. Lawless, and K. J. Boor. 2001. Quantitative descriptive analysis and principal component analysis for sensory characterization of ultrapasteurized milk. J. Dairy Sci. 84:12-20.

Deibler, K. D., E. H. Lavin, R. S. T. Linforth, A. J. Taylor, and T. E. Acree. 2001. Verification of a mouth simulator by in vivo measurements. J. Agric. Food Chem. 49:1388-1393.

Delahunty, C. M., and M. A. Drake. 2004. Sensory characteristics of cheese and its evaluation. In Cheese; Chemistry, Physics and Microbiology. Vol. I. General Aspects. 3rd ed. P. F. Fox, P. L. H. McSweeney, T. M. Cogan, and T. P. Guinee, eds. Elsevier, London, UK. (accepted)

Delahunty, C. M., and J. M. Murray. 1997. Organoleptic evaluation of cheese. Pages 90-97 in Proceedings of the 5th Cheese Symposium. T. M. Cogan, P. F. Fox, and R. P. Ross, ed. Dairy Products Research Centre, Fermoy.
Drake, M. A., T. D. Boylston, K. D. Spence, and B. G. Swanson. 1996. Chemical and sensory effects of Lactobacillus adjunct in Cheddar cheese. Food Res. Int. 29:381-387.

Drake, M. A., T. D. Boylston, K. D. Spence, and B. G. Swanson. 1997. Improvement of sensory quality of reduced fat Cheddar cheese with a Lactobacillus adjunct. Food Res. Int. 30:35-40.

Drake, M. A., and G. V. Civille. 2003. Flavor lexicons. Comp. Rev. Food Sci. 2:33-40.

Drake, M. A., P. D.Gerard, J. P. Kleinhenz, and W. J. Harper. 2003a. Application of an electronic nose to correlate with descriptive sensory analysis of aged Cheddar cheese. Lebensm.-Wiss. U.Technol. 36:13-20.

Drake, M. A., P. D. Gerard, S. Wright, K. R. Cadwallader, and G. V. Civille. 2002. Cross validation of a sensory language for Cheddar cheese. J. Sensory Stud. 17:215-229.

Drake, M. A., Y. Karagul-Yuceer, K. R. Cadwallader, G. V. Civille, and P. S. Tong. 2003b. Determination of the sensory attributes of dried milk powders and dairy ingredients. J. Sensory Stud. 18:199-216.

Drake, M. A., M. D. Keziah, P. D. Gerard, C. M. Delahunty, E. M. Sheehan, R. P. Turnbull, and T. M. Dodds. 2003c. Comparison of differences between lexicons for descriptive analysis of Cheddar cheese flavor in Ireland, New Zealand, and the United States. Abstr. P139 in 5th Pangborn Sensory Science Symp., Boston, MA.

Drake, M. A., S. C. McIngvale, K. R. Cadwallader, and G. V. Civille. 2001. Development of a descriptive sensory language for Cheddar cheese. J. Food Sci. 66:1422-1427.

Fenelon, M. A., T. P. Guinee, C. Delahunty, J. Murray, and F. Crowe. 2000. Composition and sensory attributes of retail Cheddar cheese with different fat contents. J. Food Comp. Anal. 13:13-26.

Friedrich, J. E., and T. E. Acree. 1998. Gas chromatography olfactometry $(\mathrm{GC} / \mathrm{O})$ of dairy products. Int. Dairy J. 8:235-241.

Foegeding, E. A., J. Brown, M. A. Drake, and C. R. Daubert. 2003. Sensory and mechanical aspects of cheese texture. Int. Dairy J. 13:585-591.

Hunter, E. A., and J. A. McEwan. 1998. Evaluation of an international ring trial for sensory profiling of hard cheese. Food Qual. Pref. 9:343-354.

Karagul-Yuceer, Y. K., M. A. Drake, and K. R. Cadwallader. 2003a Evaluation of the character impact odorants in skim milk powder by sensory studies on model mixtures. J. Sensory Stud. (accepted)

Karagul-Yuceer, Y. K., K. Vlahovich, M. A. Drake, and K. R. Cadwallader. 2003. Characteristic aroma components of rennet casein. J. Agric. Food Chem. 51:6797-6801.

Lawless, H. T., and H. Heymann. 1998. Sensory Evaluation of Food: Practices and Principals. Chapman and Hall, New York.

Lawlor, J. B., and C. M. Delahunty. 2000. The sensory profile and consumer preference for ten specialty cheeses. Int. Dairy Tech. J. 53:28-36.

Lynch, C. M., D. D. Muir, J. M. Banks, P. L. H. McSweeney, and P. F. Fox. 1999. Influence of adjunct cultures of Lactobacillus paracasei ssp paracasei on Cheddar cheese repening. J. Dairy Sci. 82:1618-1628.

McBride, R. L., and C. Hall. 1979. Cheese grading v. consumer acceptability: An inevitable discrepancy. Aust. J. Dairy Technol. 34:66-68.

McEwan, J. A., J. D. Moore, and J. S. Colwill. 1989. The sensory characteristics of Cheddar cheese and their relationship with acceptability. J. Soc. Dairy Technol. 42:112-117.

McGorrin, R. J. 2002. Character impact compounds: Flavors and off-flavors in foods. Pages 375-413 in Flavor, Fragrance, and Odor Analysis. R. Marsili, ed. Marcel Dekker, Inc., New York, NY.

Meilgaard, M. C., G. V. Civille, and B. T. Carr. 1999. Sensory Evaluation Techniques. 3rd ed. CRC Press, Boca Raton, FL.

Milo, C., and G. A. Reineccius. 1997. Identification and quantification of potent odorants in regular-fat and low-fat mild Cheddar cheese. J. Agric. Food Chem. 45:3590-3594. 
Monnet, J. C., F. Berodier, and P. M. Badot. 2000. Characterization and localization of a cheese georegion using edaphic criteria (Jura Mountains, France). J Dairy Sci. 83:1692-1704.

Muir, D. D., J. M. Banks, and E. A. Hunter. 1996. Sensory properties of Cheddar cheese: Effect of starter type and adjunct. Int. Dairy J. 6:407-423.

Muir, D. D., J. M. Banks, and E. A. Hunter. 1997. A comparison of flavour and texture of Cheddar cheese of factory or farmhouse origin. Int. Dairy. J. 7:479-485.

Muir, D. D., and E. A. Hunter. 1992. Sensory evaluation of Cheddar cheese: The relation of sensory properties to perception of maturity. J. Soc. Dairy Technol. 45:23-30.

Murray, J. M., and C. M. Delahunty. 2000a. Mapping preference for the sensory and packaging attributes of Cheddar cheese. Food Qual. Pref. 11:419-435.

Murray, J. M., and C. M. Delahunty. 2000b. Selection of standards to reference terms in a Cheddar cheese flavour language. J. Sensory Stud. 15:179-199.

Murray, J. M., and C. M. Delahunty. 2000c. Consumer preference for Irish farmhouse and factory cheeses. Ir. J. Agric. Food Res. 39:433-449.

Murray, J. M., C. M. Delahunty, and I. A. Baxter. 2001. Descriptive sensory analysis: Present and future. Food Res. Int. 34:461-471.

Nielson, R.G., and M. Zannoni. 1998. Progress in developing an international protocol for sensory profiling of hard cheese. Int. J. Dairy Technol. 51:57-64.

Piggott, J. R., and R. G. Mowat. 1991. Sensory aspects of maturation of Cheddar cheese by descriptive analysis. J. Sensory Stud. 6:49-62.

Preininger, M., R. Warmke, and W. Grosch. 1996. Identification of the character impact flavour compounds of Swiss cheese by sensory studies of models. Z. Lebensm. Unters Forsch 202:30-34.

Rehman, S. U., N. Farkye, and M. A. Drake. 2003a. Effects of standardization of whole milk with dry milk protein concentrate on the yield and ripening of reduced-fat Cheddar cheese. J. Dairy Sci. 86:1608-1615.

Rehman, S. U., N. Farkye, and M. A. Drake. 2003b. Reduced-fat Cheddar cheese from a mixture of cream and liquid milk protein concentrate. Int. J. Dairy Technol. 56:94-98.

Rehman, S. U., N. Farkye, and M. A. Drake. 2003c. The ripening of smoked Cheddar cheese. J. Dairy Sci. 86:1910-1917.

Roberts, A. K., and Z. M. Vickers. 1994. Cheddar cheese aging: changes in sensory attributes and consumer acceptance. J. Food Sci. 59:328-334.

Rychlik, M., R. Warmke, and W. Grosch. 1997. Ripening of Emmental cheese wrapped in foil with and without addition of Lactobacillus casei ssp. casei. III. Analysis of character impact flavour compounds. Lebensm. Wiss. Technol. 30:471-478.

Singh, T., M. A. Drake, and K. R. Cadwallader. 2003. Flavor of Cheddar cheese: A chemical and sensory perspective. Compr. Rev. Food Sci. 2:139-162.

Suriyaphan, O., M. A. Drake, X. Q. Chen, and K. R. Cadwallader. 2001. Characteristic aroma components of British farmhouse Cheddar cheese. J. Agric. Food Chem. 49:1382-1387.

Van Ruth, S. M., and C. H. O'Connor. 2001. Evaluation of three gas chromatography-olfactometry methods: comparison of odour intensity-concentration relationships of eight volatile compounds with sensory headspace data. Food Chem. 74:341-347.

Young, N., M. A. Drake, K. Lopetcharat, and M. McDaniel. 2004. Preference mapping of Cheddar cheeses. J. Dairy Sci. 87:11-19.

Zehentbauer, G., and G. A. Reineccius. 2002. Determination of key aroma components of Cheddar cheese using dynamic headspace dilution assay. Flavour Fragr. J. 17:300-305. 